\title{
DETERMINATION OF THE PESTICIDES IN WATER USED IN THE CULTURE AND PROCESSING OF POTATOES
}

\author{
Patrícia H. Ribeiro ${ }^{a}$, Lêda R. A. Faroni ${ }^{a}$, ,(i), Fernanda F. Heleno ${ }^{\mathrm{b}}$, Maria E. L. R. de Queiroz ${ }^{\mathrm{c}}$ and Lucas H. F. Prates ${ }^{\mathrm{a}}$ \\ aDepartamento de Engenharia Agrícola, Universidade Federal de Viçosa, 36570-900 Viçosa - MG, Brasil \\ berviço Autônomo de Água e Esgoto, 36540-970 Senador Firmino - MG, Brazil \\ 'Departamento de Química, Universidade Federal de Viçosa, 36570-900 Viçosa - MG, Brasil
}

Recebido em 11/02/2020; aceito em 05/05/2020; publicado na web em 24/06/2020

\begin{abstract}
The contamination of water bodies by pesticide residues through direct flow, leaching and other methods has motivated the development of analytical methods for the determination of these compounds in water. A vortex-assisted liquid-liquid microextraction method followed by gas chromatography coupled to mass spectrometry for the determination of anilazine, linuron, prothiofos, and tebuconazole residues in water samples from the culture and processing of potatoes (Solanum tuberosum L.) was optimized. The complete factorial design and the central rotational compound design combined with the desirability function were used to evaluate and optimize the parameters of the method. The optimized conditions for extracting the pesticides were as follows: $316 \mu \mathrm{L}$ of toluene, no sodium chloride addition, and a stirring time of $187 \mathrm{~s}$. The method presented an enrichment factor of 142.4 times and good linearity, precision and accuracy, with limits of detection (LOD) of $0.005-0.007 \mathrm{mg} \mathrm{L}^{-1}$ and limits of quantification (LOQ) of $0.016-0.022 \mathrm{mg} \mathrm{L}^{-1}$. The co-extractives of the wastewater samples caused the suppression of the chromatographic response of linuron and prothiofos by 7.82 and $27.63 \%$, respectively. The analyte concentrations in the wastewater samples from the industrial shing process, manual potato washing, and dam water were either lower than the LODs of the method or were absent.
\end{abstract}

Keywords: vortex-assisted liquid-liquid microextraction; wastewater; Solanum tuberosum L.

\section{INTRODUCTION}

Pesticides have the potential to prevent and control organisms that are harmful to crops in general, making them a powerful tool for agriculture. ${ }^{1}$ These compounds comprise a large number of substances with different levels of persistence, which are divided into different classes: herbicides, fungicides and insecticides among others. ${ }^{2}$ There are estimations that approximately one-third of all agricultural production would be lost if these substances were not used. $^{3}$

Brazil is a great user of pesticides, consuming $20 \%$ of the pesticides traded worldwide. ${ }^{4}$ Despite benefitting the global food supply and maximizing the economic gain from agricultural activities, the use of pesticides can cause environmental problems, including soil, water, and food contamination. ${ }^{5,6}$

Pesticide residues can reach the environment by direct flow and leaching from regions where they have been applied, the careless disposal of empty product containers and the washing of equipment that has been used with the pesticides. ${ }^{1}$

In the handling and processing of different crops, the volume of wastewater is quite high, causing the contamination of water bodies. One crop that has this problem is potato (Solanum tuberosum L.), the third most consumed food in the world, ${ }^{7}$ and in Brazil, it is considered the main vegetable both in cultivated area and in food preference. $^{8}$

Water is widely used in the washing of tubers from the beginning of the process until the time before its commercialization because consumers often reject tubers without washing. ${ }^{9}$ Potato processing generates a considerable pollutant load due to the presence of a large number of organic compounds (bark and starch residues) in the wastewater. Contamination by residues of pesticides present in the soil adhered to tubers can also occur because in potato cultivation, as in

\footnotetext{
*e-mail: 1faroni@ufv.br
}

other crops, the intensive and constant use of pesticides is necessary for controlling pests, diseases and invasive plants to minimize losses, productivity and product quality. ${ }^{10}$

There are large differences between Brazilian and other legislation on acceptable limits of residues in water and food. The contamination of water is what most attracts attention, since Brazilian law allows, for example, limits five thousand times the maximum allowed by the European Union in drinking water for some pesticides. ${ }^{4}$

The contamination of water bodies by pesticides has been the subject of worldwide concern, motivating the development of several analytical methods for the determination of these compounds in water. ${ }^{11,12}$

Liquid-liquid extraction (LLE) and solid phase extraction (SPE) are sample preparation methods traditionally used for the determination of pesticides in water. ${ }^{13}$ Despite providing precise and accurate results, in general, these conventional methods present some drawbacks, such as consuming high amounts of toxic organic solvents and samples in addition to having relatively high costs. ${ }^{14}$ To overcome these limitations, the dispersive liquid-liquid microextraction (DLLME) methodology was developed..$^{1,15}$

Dispersive liquid-liquid microextraction (DLLME) has been proposed as an alternative because it is a simple and fast extraction method with a high enrichment factor, high recovery and low cost. However, DLLME also has some disadvantages, such as the difficulty of automating and the need to use a third component (a dispersing solvent), which can decrease the partition coefficient of the analytes in the extraction solvent. ${ }^{16}$

A microextraction method called vortex-assisted liquidliquid microextraction (VALLME), developed by Yiantzi et al. ${ }^{17}$ demonstrated that the dispersion of the solvent of low-density extraction in water is obtained by vortexing, intensifying the process of dispersion of the extracting solvent and contributing to increasing the contact surface between the organic phase (extraction solvent) and the aqueous phase (sample). This stirring favours the partitioning of 
the target compounds between the two immiscible phases. ${ }^{18,19}$ With stirring and subsequent centrifugation, the extraction solvent restores its initial single drop form,${ }^{16}$ and thus, VALLME can suppress the use of the dispersing solvent and solve a classic DLLME problem, which is its main advantage. ${ }^{20}$ VALLME has undergone numerous adaptations that include the simplification of steps and the use of different modes of agitation and extractive solvents with different physicochemical properties among others. ${ }^{20}$

The application of these methodologies for the determination of pesticides in wastewater samples still requires investigation since the number of publications with pesticide residue data in these waters is limited. Thus, the present work aimed to develop a method of extracting pesticides in water for the simultaneous determination of the pesticides of different classes used in potato cultivation. In addition, the applicability of the developed method was evaluated in different samples of wastewater: wastewater from a factory of potato chips, wastewater from the handwashing of contaminated potatoes purchased in a local market, and the natural water used for irrigation collected from a dam located in an area with commercial potato production.

\section{EXPERIMENT}

\section{Reagents and solutions}

The solutions used in this study were prepared from the analytical standards of the fungicides anilazine (99.9\%, Sigma Aldrich, St. Louis, MO, USA) and tebuconazole (99.3\%, Sigma Aldrich), the herbicide linuron (99.7\%, Sigma Aldrich) and the acaricide/ insecticide prothiofos $(99.8 \%$, Sigma Aldrich) using acetonitrile (99.9\%, Sigma Aldrich) as the solvent. Stock solutions of $1000 \mathrm{mg} \mathrm{L}^{-1}$ of each pesticide were prepared in acetonitrile, and subsequent dilutions of these solutions were prepared to contain the analytes at different concentrations according to the study step. The solutions were stored in a freezer at $-20^{\circ} \mathrm{C}$. Toluene $(99.9 \%$, Sigma Aldrich), hexane (99\%, Vetec, Duque Caxias, RJ, Brazil) and cyclohexane (99\%, Vetec) were used as the extraction solvents. Sodium chloride (99.5\%, Alphatec, São José dos Pinhais, PR, Brazil) was used to adjust the ionic strength of the samples.

Acetone (99.5\%, Vetec), the alkaline detergent MA-01 (Merck, Rio de Janeiro, RJ, Brazil) and nitric acid (65\%, Química Moderna, Barueri, SP, Brazil) were used to clean the glass materials used.

\section{Chromatograph conditions}

The presence of pesticide residues in the water samples fortified with anilazine, linuron, prothiofos and tebuconazole was analysed in a GC-MS system composed of a 7820A gas chromatograph (GC) coupled to a 5977B mass spectrometer (MS) (Agilent Technologies, Palo Alto, CA, USA). The CG-MS was operated in full scan mode (mass acquisition interval $\mathrm{m} / \mathrm{z}, 50-450$ ) with an ionization energy of $70 \mathrm{eV}$ in splitless mode with an injector temperature at $280{ }^{\circ} \mathrm{C}$. The HP-5M capillary column (30 m x $0.25 \mathrm{~mm}$ x $0.25 \mu \mathrm{m}$; Agilent Technologies, Palo Alto, CA, USA) was used for the separation. The initial temperature of the column was $150^{\circ} \mathrm{C}$ (maintained for $1 \mathrm{~min}$ ), with a heating rate of $30^{\circ} \mathrm{C} \mathrm{min}-1$ to $290{ }^{\circ} \mathrm{C}$, which was maintained for 3 min. Analytical helium 5.0 (99.999\%, White Martins, Rio de Janeiro, RJ, Brazil) was used as the carrier gas in the column at a flow rate of $1.2 \mathrm{~mL} \mathrm{~min}^{-1}$. The solvent cut time was $2.9 \mathrm{~min}$. The volume of an injected sample was $1.0 \mu \mathrm{L}$, and the total running time was $8.67 \mathrm{~min}$. The mass spectrum was compared to the NIST version 2.2 database.

\section{Optimization of the extraction conditions}

\section{Univariate optimization - extraction solvents}

For the extraction of the pesticides in the fortified water samples, the extraction solvent volume and the vortexing time were fixed, and three extraction solvents were evaluated: toluene, hexane, and cyclohexane.

The method consisted of placing the following separately in $50 \mathrm{~mL}$ volumetric flasks: $450 \mu \mathrm{L}$ aliquots of the extraction solvent (toluene, hexane or cyclohexane) and $45 \mathrm{~mL}$ of deionized water containing $0.1 \mathrm{mg} \mathrm{L}^{-1}$ of each of the target analytes. The flasks were then closed and vortexed (MA-162, Marconi, Piracicaba, SP, Brazil) at $2000 \mathrm{rpm}$ for $90 \mathrm{~s}$. An aliquot of $5 \mathrm{~mL}$ of deionized water was added with a pipette immediately after shaking for the flotation of the extraction solvent. After 10 minutes of rest, the separation of the two phases naturally occurred in the volumetric flask. The volume of supernatant solvent was collected with a micropipette and transferred into an insert that was put in a vial and stored at $-20{ }^{\circ} \mathrm{C}$ until further use for chromatographic analysis. An aliquot of $1 \mu \mathrm{L}$ of the collected solution was injected into the GC-MS for chromatographic analysis. The comparison of the mean values of the chromatographic areas of the pesticides ( $n=6$ points) extracted by the three solvents was performed by the ANOVA and Tukey test at $5 \%$ probability.

\section{Multivariate optimization - Volume of the solvent, salt addition, and stirring time}

The vortex-assisted liquid-liquid microextraction method (VALLME) is the combination of the pesticide extraction steps of the liquid matrix and sample concentration. During this procedure, many factors can affect the extraction efficiency. To evaluate and optimize the most important parameters that affect the efficiency of the extraction of residues of the four pesticides by the VALLME method, a full factorial design was used to determine the significant factors in the extraction method, and a central composite design (CCD) was used to estimate the best experimental conditions.

After selecting the best extraction solvent, the $45 \mathrm{~mL}$ aliquots of the samples were placed separately in $50 \mathrm{~mL}$ volumetric flasks with different amounts of $\mathrm{NaCl}(0-20 \%(w / v))$ together with the previously selected extraction solvent $(316-534 \mu \mathrm{L})$. The flasks were then sealed and vortexed by different stirring times (40 - $187 \mathrm{~s})$ at $2000 \mathrm{rpm}$. Immediately after stirring, $5 \mathrm{~mL}$ of deionized water was added with a volumetric pipette in each flask to float the extraction solvent. The separation of the extraction solvent was similar to the step of choosing the solvent.

The full factorial model generated by the statistical software (Statistica, Statsoft Inc., Tulsa, OK, USA) describes the influence of the combination of the three variables tested on their chromatographic responses. The three independent variables evaluated were the stirring time $\left(\mathrm{X}_{1}, 60-120 \mathrm{~s}\right)$, the percentage of $\mathrm{NaCl}$ in the extraction solution $\left(\mathrm{X}_{2}, 4-16 \%\right)$ and the volume of the extraction solvent $\left(\mathrm{X}_{3}\right.$, $400-500 \mu \mathrm{L})$. The main effect of each variable was investigated in 20 tests determined from the expression $2^{\mathrm{n}}+2=10$, with $\mathrm{n}=3$ independent variables; thus, $2^{3}$ ( $(8$ cubic points $)+(2$ central points $)=$ 10 tests) were performed in duplicate based on the experimental design described in Table 1. The analyses of the response variables were performed in triplicate. The experimental results were evaluated according to the chromatographic responses (areas), and the effects of the factors were illustrated in a Pareto chart.

To determine the optimum conditions of extraction of the pesticides to obtain the best chromatographic responses, the three independent variables, i.e., the volume of the extraction solvent, the percent $\mathrm{NaCl} \mathrm{w} / \mathrm{v}$ in the extraction solution, and the stirring time, 
were studied in five levels $(-1.68,-1,0,+1$, and +1.68$)$ in a central composite design (CCD). The total number of tests was 32, which was determined from the expression $2^{n}+2 n+2=16$, with $n=3$; thus, $2^{3}((8$ cubic points $)+2 \times 3(6$ axial points $)+2$ (central points $)=$ 16 tests) were performed in duplicate (Table 2 ).

The obtained data were submitted to regression analysis. The effects of each variable and their interactions in the determination of the different classes of pesticides in water were calculated using Statistica 13.0 software (Statsoft Inc., Tulsa, OK, USA). The models were chosen based on the significance of the regression coefficients, the determination coefficient $\left(\mathrm{R}^{2}\right)$, the residue analysis, the lack of fit, and the biological phenomenon. The data were presented in graphs generated by the software SigmaPlot 12.5 (Systat Software, Inc., San Jose, CA, USA). The analyses of the response variables were performed in triplicate.

\section{Merit parameters of the method}

The selectivity of the analytical method was evaluated by comparing the chromatograms of the extracts of a pesticide-free matrix (deionized water free of the studied analytes) with the chromatograms of the extracts of extracts of the fortified matrix with the pesticides studied at a concentration of $0.1 \mathrm{mg} \mathrm{L}^{-1}$. To obtain the extracts, the samples were submitted to the optimized VALLME extraction procedure.

The linearity of the method was evaluated through the calibration curve obtained by the analysis of the fortified samples with pesticide concentrations ranging from $0,05-0,15 \mathrm{mg} \mathrm{L}^{-1}(\mathrm{n}=5$ points). The mathematical relationship between the signal (response) and the concentration of the target analyte was expressed by the calibration curve equation and its correlation coefficient (r).

Table 1. Experimental factors and levels of the full factorial design

\begin{tabular}{|c|c|c|c|c|c|c|}
\hline \multirow{2}{*}{ Assay } & \multicolumn{3}{|c|}{ Coded variables } & \multicolumn{3}{|c|}{ True variables } \\
\hline & $\mathrm{X}_{1}$ & $\mathrm{X}_{2}$ & $\mathrm{X}_{3}$ & Stirring time (s) & $\mathrm{NaCl}(\%)$ & Extraction solvent $(\mu \mathrm{L})$ \\
\hline 1 and 11 & -1 & -1 & -1 & 60 & 4 & 400 \\
\hline 2 and 12 & +1 & -1 & -1 & 120 & 4 & 400 \\
\hline 3 and 13 & -1 & +1 & -1 & 60 & 16 & 400 \\
\hline 4 and 14 & +1 & +1 & -1 & 120 & 16 & 400 \\
\hline 5 and 15 & -1 & -1 & +1 & 60 & 4 & 500 \\
\hline 6 and 16 & +1 & -1 & +1 & 120 & 4 & 500 \\
\hline 7 and 17 & -1 & +1 & +1 & 60 & 16 & 500 \\
\hline 8 and 18 & +1 & +1 & +1 & 120 & 16 & 500 \\
\hline 9 and $19(\mathrm{C})$ & 0 & 0 & 0 & 90 & 10 & 450 \\
\hline 10 and $20(\mathrm{C})$ & 0 & 0 & 0 & 90 & 10 & 450 \\
\hline
\end{tabular}

$\mathrm{C}=$ central point.

Table 2. Central composite design (CCD) to evaluate the effects of the volume of the extraction solvent, the percent $\mathrm{NaCl}(\mathrm{w} / \mathrm{v})$, and the stirring time at the determination of the pesticides anilazine, linuron, prothiofos, and tebuconazole in water

\begin{tabular}{|c|c|c|c|c|c|c|}
\hline \multirow{2}{*}{ Assay } & \multicolumn{3}{|c|}{ Coded variables } & \multicolumn{3}{|c|}{ True variables } \\
\hline & $\mathrm{X}_{1}$ & $\mathrm{X}_{2}$ & $\mathrm{X}_{3}$ & Extraction solvent $(\mu \mathrm{L})$ & $\mathrm{NaCl}(\%)$ & Stirring time (s) \\
\hline 1 and 17 & -1 & -1 & -1 & 350 & 1.6 & 80 \\
\hline 2 and 18 & -1 & -1 & +1 & 350 & 1.6 & 160 \\
\hline 3 and 19 & -1 & +1 & -1 & 350 & 6.4 & 80 \\
\hline 4 and 20 & -1 & +1 & +1 & 350 & 6.4 & 160 \\
\hline 5 and 21 & +1 & -1 & -1 & 450 & 1.6 & 80 \\
\hline 6 and 22 & +1 & -1 & +1 & 450 & 1.6 & 160 \\
\hline 7 and 23 & +1 & +1 & -1 & 450 & 6.4 & 80 \\
\hline 8 and 24 & +1 & +1 & +1 & 450 & 6.4 & 160 \\
\hline 9 and 25 & -1.68 & 0 & 0 & 316 & 4.0 & 120 \\
\hline 10 and 26 & +1.68 & 0 & 0 & 484 & 4.0 & 120 \\
\hline 11 and 27 & 0 & -1.68 & 0 & 400 & 0.0 & 120 \\
\hline 12 and 28 & 0 & +1.68 & 0 & 400 & 8.0 & 120 \\
\hline 13 and 29 & 0 & 0 & -1.68 & 400 & 4.0 & 52 \\
\hline 14 and 30 & 0 & 0 & +1.68 & 400 & 4.0 & 187 \\
\hline 15 and $31(\mathrm{C})$ & 0 & 0 & 0 & 400 & 4.0 & 120 \\
\hline 16 and $32(\mathrm{C})$ & 0 & 0 & 0 & 400 & 4.0 & 120 \\
\hline
\end{tabular}

$\mathrm{C}=$ central point. 
The limits of detection (LOD) and quantification (LOQ) were calculated by the relation between the standard deviation of the slope of the response calibration curve ( $n=3$ points). The resulting value was multiplied by 3.3 to obtain the LOD and by 10 to obtain the LOQ. ${ }^{21}$

Precision was expressed in terms of repeatability and intermediate precision. To determine the repeatability, the samples were fortified in five replicates and at three concentrations $(0.100,0.125$, and $\left.0.150 \mathrm{mg} \mathrm{L}^{-1}\right)$. To determine the intermediate precision, the samples were fortified in five replicates at three concentrations $(0.100,0.125$, and $0.150 \mathrm{mg} \mathrm{L}^{-1}$ ) and on three different days. The results were expressed by the coefficient of variation.

Accuracy was determined from recovery assays in which known quantities of analyte were added to a sample in five replicates of three different concentrations $\left(0.100,0.125\right.$ and $\left.0.150 \mathrm{mg} \mathrm{L}^{-1}\right)$. The results were expressed as percentage recovery.

\section{Enrichment factor}

The enrichment factor (EF) was used to evaluate the extraction performance. EF is defined as the ratio of the sample volume $(45 \mathrm{~mL})$, and the extractor solvent volume $(316 \mu \mathrm{L})$, used in optimized VALLME extraction procedure.

The matrix effect was evaluated by comparing the calibration curve of the analytical standard addition at concentrations of 0.50 , $0.75,1.00,1.25$ and $1.50 \mathrm{mg} \mathrm{L}^{-1}$ in wastewater from the washing and peeling process of potatoes collected in a straw potato factory with the calibration curve of analytical standard addition at concentrations of $0.050,0.075,0.100,0.125$ and $0.150 \mathrm{mg} \mathrm{L}^{-1}$ in pure water for the VALLME extraction according to the parallelism test. The percentage of the matrix effect was given by the difference in the slope of the analytical curve of the potato residue matrix and in pure water, [((matrix slope)/pure water slope $) \times 100]$, both fortified with standards of the pesticides anilazine, linuron, prothiofos, and tebuconazole at different concentrations, as described by Meier. ${ }^{22}$

\section{Application in the wastewater samples}

The validated VALLME method was applied in triplicate to three different types of water samples to evaluate the efficiency and applicability of the proposed method.

Water 1. Wastewater from the washing and peeling process of potatoes was collected from a straw and potato chip factory located in Viçosa, Minas Gerais, Brazil. The samples were previously sieved (3.36 $\mathrm{mm}$ ) to remove coarse residues such as potato peels and sedimented soil. The water was then collected, transferred to the laboratory and allowed to stand in $65 \mathrm{~L}$ buckets for $24 \mathrm{~h}$ at $10 \pm 2{ }^{\circ} \mathrm{C}$ for the removal of settleable solids. After the settling period, the supernatant was collected, stored, and subjected to the VALLME technique.

Water 2. Wastewater from the manual washing process of raw potatoes was purchased at a local market in Viçosa, Minas Gerais, Brazil. Six litres of distilled water were used to wash eight kilograms of potatoes. The samples were collected in amber glass bottles and stored at $4 \pm 2{ }^{\circ} \mathrm{C}$ from the time of collection until the analyses were performed.

Water 3. Water used for irrigation was collected from a dam located in an area with a potato plantation, which was located in the city of Ouro Branco, Minas Gerais, Brazil. This water was collected at a depth of $30 \mathrm{~cm}$ at points near the banks of the dam immediately after the first rain that occurred after harvesting the potato field (approximately 30 days after harvest). The samples were collected in amber glass bottles and conditioned at $4 \pm 2{ }^{\circ} \mathrm{C}$ from the time of collection until the analyses were performed.
In the application of the VALLME technique for the potato washing water analysis (Water 1), changes in the method were required because of the large amount of emulsion formed during the stirring of the sample and the small amount of extraction solvent floating in the upper phase after the phase separation.

Given the high content of suspended solids $\left(1756.25 \mathrm{mg} \mathrm{L}^{-1}\right)$ and high organic matter load (total organic carbon $(\mathrm{TOC})=537.2 \mathrm{mg} \mathrm{L}^{-1}$ ) of Water 1 , it was necessary to make dilutions with distilled water (5x) to reduce the formation of emulsion after shaking the samples and allow the separation of the phases. However, the supernatant still presented an emulsion in Water 1 (diluted) and water 2, necessitating the collection of the supernatant with a syringe and filtering the samples with $0.45 \mu \mathrm{m}$ hydrophilic PTFE membrane syringe filters (Filtrilo, Colombo, PR, Brazil). For the separation of the water present in the emulsion, the filtrate was retained in vials and stored at -20 ${ }^{\circ} \mathrm{C}$ until the freezing of the aqueous phase to facilitate the separation of the organic phase that remained in a liquid state. The supernatant solvent was then collected with a micropipette and transferred to an insert, which was placed in a vial and stored at $-20{ }^{\circ} \mathrm{C}$ until further use for chromatographic analysis.

\section{RESULTS AND DISCUSSION}

\section{Optimization of the extraction parameters}

To obtain a high extraction of the analytes, the effects of different factors were investigated. The chromatographic response was used as a key parameter during the optimization of the extraction method.

\section{Effect of the extraction solvent}

The selection of an appropriate extraction solvent is important in the VALLME technique to obtain a high extraction rate. Among the main requirements for the selection of an extraction solvent for this method are a low miscibility in water, a density lower than that of water, a high extraction efficiency for the target analytes and good chromatographic behaviour. ${ }^{23}$ Based on these considerations, toluene (density $0.87 \mathrm{~g} \mathrm{~cm}^{-3}$; solubility of $0,05 \mathrm{~g} / 100 \mathrm{~mL}$ in water at $20{ }^{\circ} \mathrm{C}$ ), hexane (density $0.66 \mathrm{~g} \mathrm{~cm}^{-3}$; insoluble in water at $20^{\circ} \mathrm{C}$ ) and cyclohexane (density $0.81 \mathrm{~g} \mathrm{~cm}^{-3}$; insoluble in water at $20^{\circ} \mathrm{C}$ ) were selected as potential extraction solvents for this study. The effect of the extraction of all four pesticides with three solvents was subjected to F-test in one-way analysis of variance. The results were statically significant with a p-value less than 0.05 for the extraction of all pesticides, except for prothiofos with a p-value of 0.2038 . Toluene presented the best results for all the pesticides subjected to the extraction method, except for prothiofos, whose chromatographic responses did not present significant difference in the extracted amounts by the three solvents evaluated after evaluation by the Tukey test (Figure 1). Therefore, toluene was the extraction solvent used in subsequent assays.

Similar results were obtained by Duarte et al., ${ }^{20}$ who also evaluated the same solvents for the simultaneous determination of pesticides from three chemical classes (triazines, triazinones, and triazole) in water using vortex- and ultrasound-assisted dispersive liquid-liquid microextraction techniques.

Compared to the other used, toluene is the most polar solvent, which may justify its higher extraction rate. ${ }^{20,24}$ Some authors have also highlighted the contribution of the aromatic structure of toluene in the extraction of unsaturated analytes. ${ }^{12,25}$

\section{Effect of the extraction solvent volume, the addition of salt and the stirring time}

The volume of the extraction solvent may affect the dispersion efficiency and consequently the mass transfer of the analyte between 


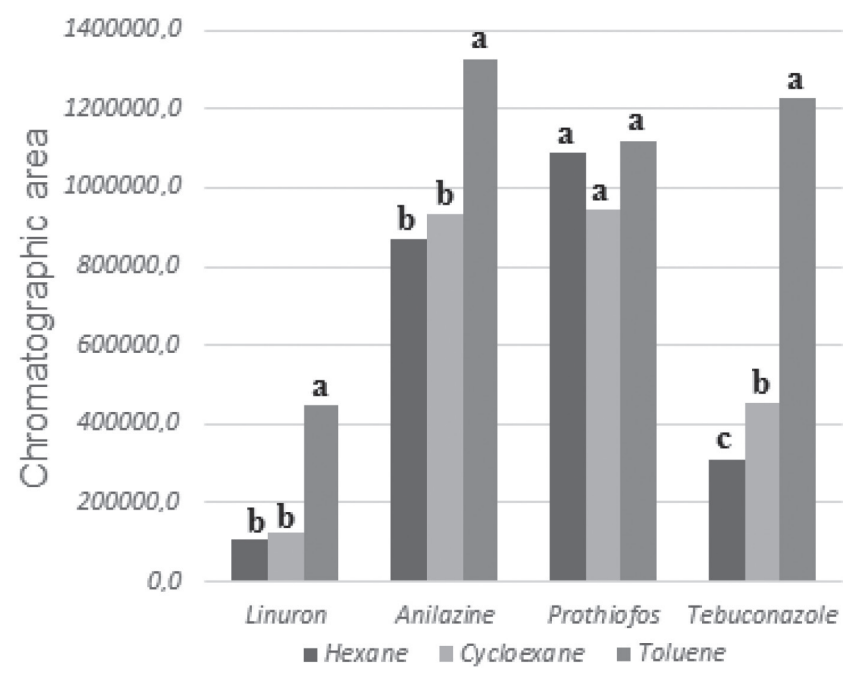

Figure 1. Chromatographic responses of the analytes with different extraction solvents. Extraction conditions: $45 \mathrm{~mL}$ of water fortified with $0.1 \mathrm{mg} \mathrm{L}^{-1}$ of each pesticide; $450 \mu L$ of extraction solvent and $90 \mathrm{~s}$ vortexing at $2000 \mathrm{rpm}$. Means with the same letter in a column for the same analyte do not differ among themselves by the Tukey test at the 5\% level of significance

the matrix and the extraction solvent. Some authors also attribute a lower recovery to the effects of diluting the extracts. ${ }^{26,27}$ It has been observed that by decreasing the volume of the extraction solvent, the LOD increases, but with very small volumes, it is not possible to collect the extraction solvent at the top of the aqueous phase.

Time and stirring speed may also influence the dispersion of the extracting solvent and the mass transfer processes and consequently the efficiency of the microextraction methods. ${ }^{28}$ When the toluene:water mixture is vortexed, the formation of microdroplets of toluene is rapidly dispersed in water. This phenomenon can be visually perceived by the turbidity of the mixture formed during the experiments. The extraction efficiency seems to be related to the efficiency of this dispersion and the size of the dispersed solvent droplets. The smaller the droplet size is, the larger the interfacial area between the water and the extraction solvent and the higher the extraction efficiency. ${ }^{20}$

The addition of salt has been widely used in liquid-liquid extraction methods due to the possibility of increasing the extraction efficiency due to the salting-out effect, where the solubility of the analytes decreases with an increase in the ionic strength, contributing to their transfer to the organic phase ${ }^{29,30}$ However, the addition of salt can decrease the solubility of a solvent in water, reducing the extraction efficiency. ${ }^{23}$

The effects of the factors evaluated in the full factorial design are illustrated in a Pareto chart (Figure 2). A Pareto chart is a statistical tool that allows a clear view of the effects of variables. ${ }^{31}$ The length of a bar is proportional to the absolute value of the main effect with $95 \%$ confidence. ${ }^{32}$

The three independent variables in the process were significant, and the volume of the extraction solvent was the factor that showed the greatest influence on the extraction, which was followed by the percentage of $\mathrm{NaCl}$ in the solution. Both had a negative effect on the extraction of pesticides, while stirring time had a positive effect. Therefore, a decrease in the extractive solvent volume and the percentage of $\mathrm{NaCl}$ in the solution and an increase in the agitation time led to the better extraction of the pesticides.

Since all the independent variables tested were significant, all the variables were optimized using a central composite design (CCD), where the volume of the extraction solvent $(350-400 \mu \mathrm{L})$ and the percentage of salt $(1.6-6.4 \%)$ decreased while the stirring time increased ( $80-160 \mathrm{~s}$ ) (Table 2$)$ in relation to the pesticide extraction process evaluated in the full factorial design (Table 1). The model for

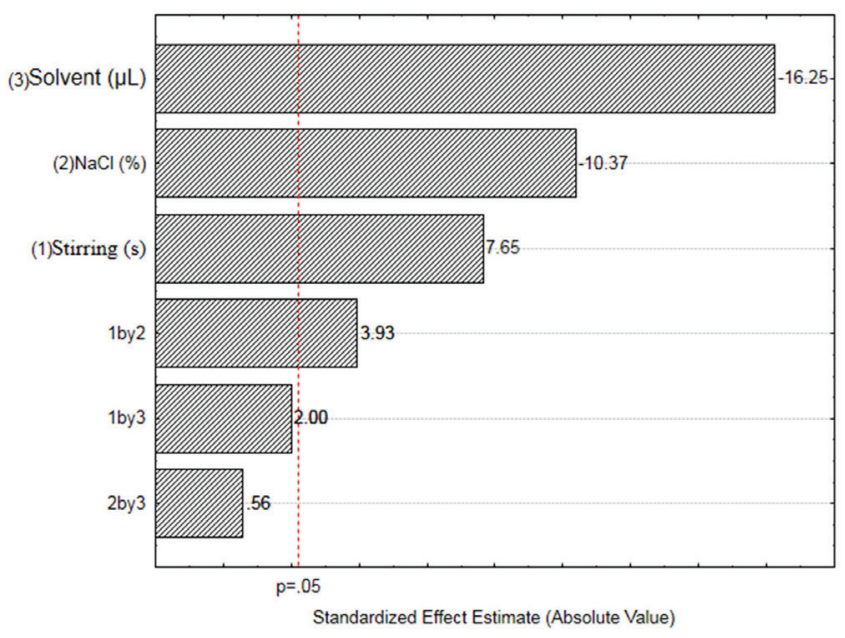

Figure 2. Pareto graph obtained from the full factorial design for the sum of the areas of the pesticides extracted by the VALLME method in water fortified with $0.1 \mathrm{mg} \mathrm{L-1}$ of anilazine, linuron, prothiofos, and tebuconazole

the determination of the pesticides anilazine, linuron, prothiofos, and tebuconazole in fortified water as a function of the extraction solvent (Es), the percentage of salt ( $\mathrm{Sa}$ ) and the stirring time $(\mathrm{St})$ in the range studied in the CCD is presented in Equation 1.

$\mathbf{Z}=12888070.917^{*}-38858.118^{*} \mathrm{Es}+34.676^{*} \mathrm{Es}^{2}-271485 \mathrm{Sa}-$ $3995 \mathrm{Sa}^{2}+6253 \mathrm{St}-4 \mathrm{St}^{2+} 696.764^{*} \mathrm{Es} \mathrm{Sa}-6 \mathrm{Es} \mathrm{St}+45 \mathrm{Es} \mathrm{St}$

*Significant at $5 \%$ by Student's t-test.

The quality of the adjustment to the response surfaces evaluated by analysis of variance (ANOVA) demonstrates a significant quadratic effect for the solvent volume and its interaction with salt addition. The coefficient of determination $\left(\mathrm{R}^{2}\right)$ indicates that 90.74 of the observed data variation can be explained by the model, demonstrating that the adjusted model is adequate. The response surface graphs confirm the results of the Pareto graph: the efficiency of the extraction is increased with 1) the decrease in the volume of the extraction solvent, 2) the decrease in salt concentration and 3) the increase in stirring time.

The response surfaces obtained for the sum of the analyte areas as a function of the stirring time, the volume of the extraction solvent, and the salt percentage are shown in Figure 3. The sum of the areas of the pesticides extracted from the fortified water increased with increased stirring time (Figure $3 \mathrm{~A}$ ) and decreased with an increased volume of solvent and the percent $\mathrm{NaCl}$ in the solution (Figure $3 \mathrm{~B}$ ).

After defining the best model, the next step was to find the values of the experimental variables that maximized the extraction of the pesticides. The desirability profiles obtained from the predicted values using the software Statistica 13.0 were considered for the optimization process.

The matrix of the optimization design CCD (Figure 4) showed that higher chromatographic areas of linuron $(4280 \mathrm{E}+2$ with a desirability of 1.0$)$, anilazine $(1428 \mathrm{E}+3$ with a desirability of 1.0$)$, prothiofos $(1173 \mathrm{E}+3$ with a desirability of 1.0$)$ and tebuconazole $(1359 \mathrm{E}+3$ with a desirability of 1.0) were obtained under the following conditions: 316 $\mu \mathrm{L}$ of the extraction solvent without salt added $(\mathrm{NaCl})$ to the extraction solution and a vortexing time of $187 \mathrm{~s}$. Therefore, the aforementioned conditions were adopted to validate the extraction technique.

\section{Method validation}

The following merit parameters of the proposed method were evaluated: selectivity, linearity, limits of detection (LOD) and quantification (LOQ), precision, and accuracy. 

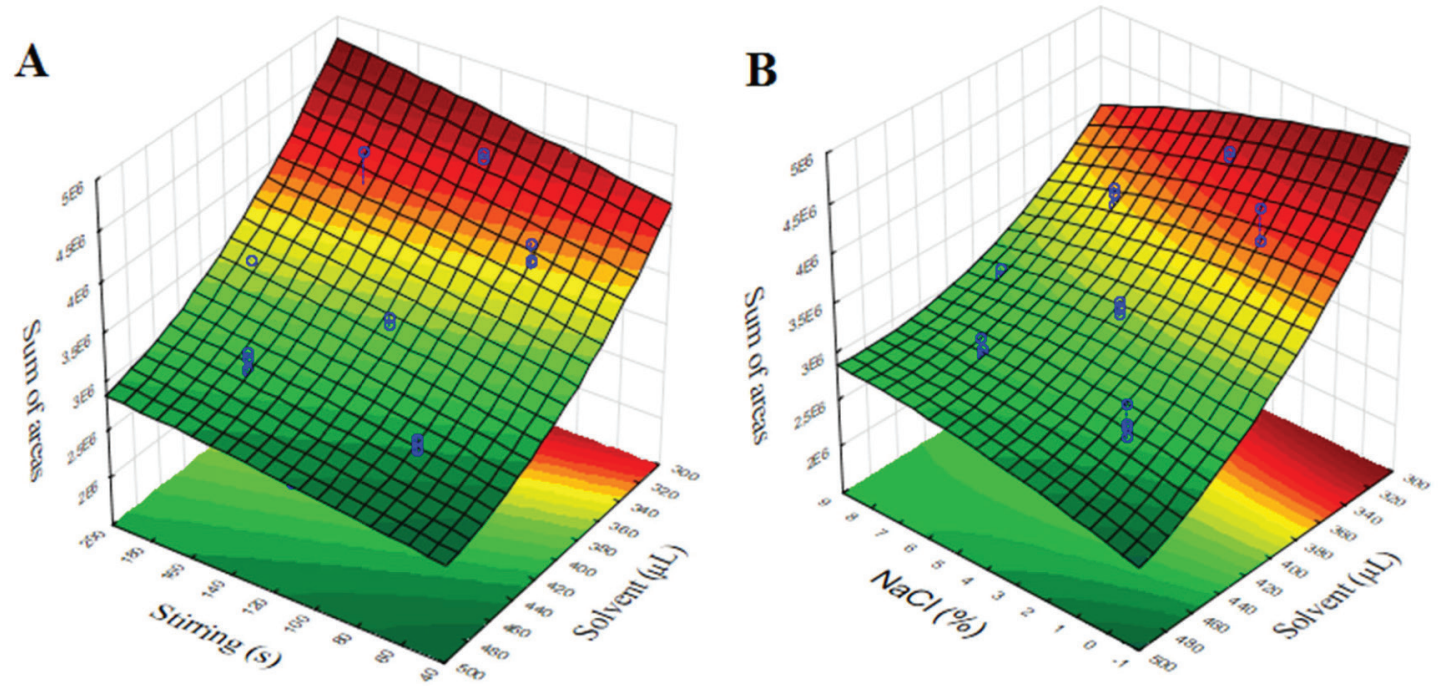

Figure 3. Surface response of the independent variables, including the stirring time (s), the volume of the extraction solvent ( $\mu L)$, and the percent of salt (\% NaCl $w / v$ ), at the estimative of the sum of the chromatographic areas from the analytes extracted from the fortified water at $0.1 \mathrm{mg} \mathrm{L}^{-1}$ of each pesticide (anilazine, linuron, prothiofos, and tebuconazole). (A) The sum of the chromatographic areas as a function of the stirring time and the volume of the solvent. (B) The sum of the chromatographic areas as a function of the percent of salt added and the volume of the extraction solvent
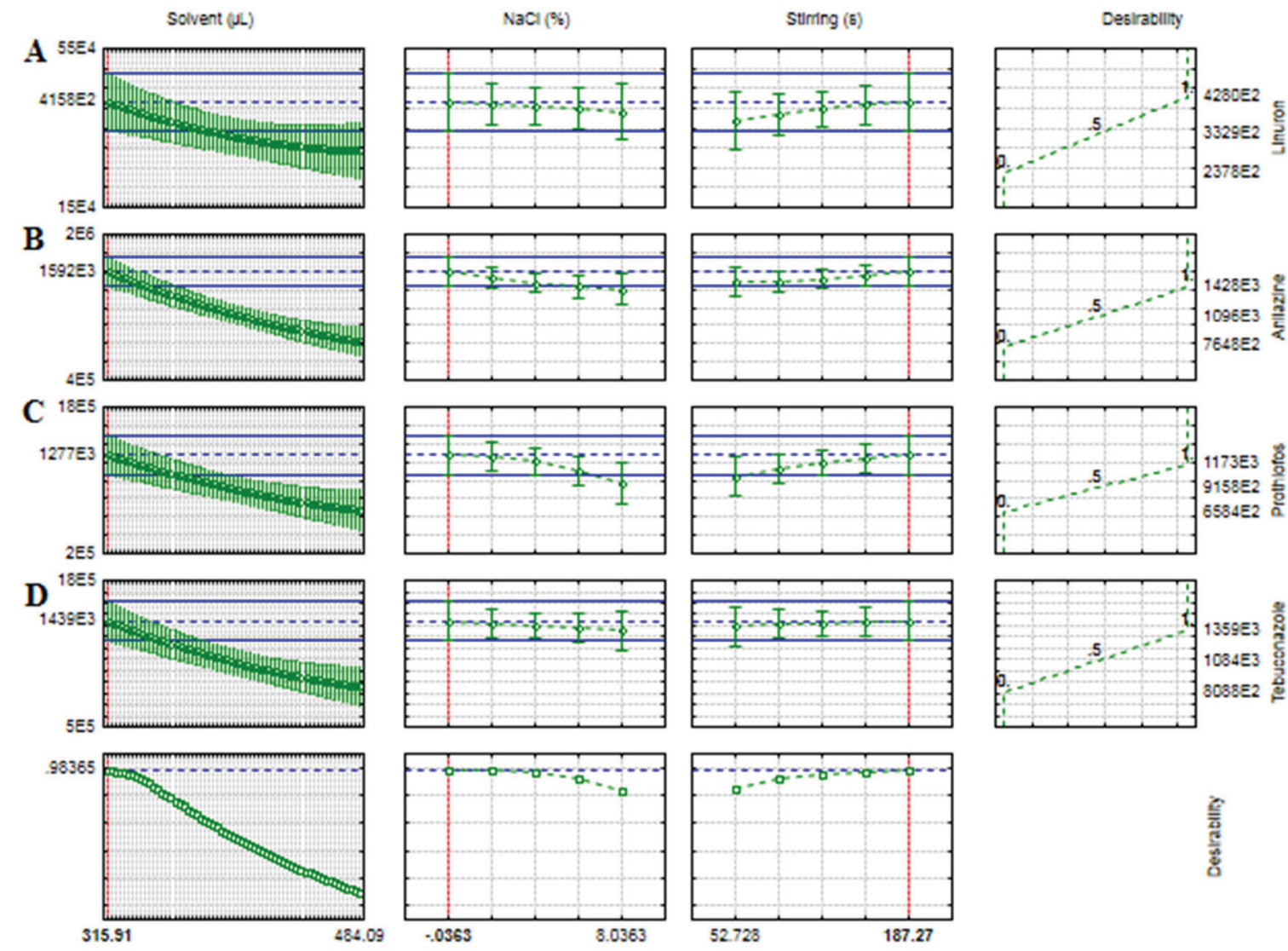

Figure 4. Profiles of the predicted values and functions of the expected values for the extraction recovery of $(A)$ linuron, $(B)$ anilazine, $(C)$ prothiofos and $(D)$ tebuconazole. Dashed lines indicate the values after the optimization

Evaluating selectivity consists of evaluating the ability of the method to separate the analyte of interest from other components present in the sample. ${ }^{33,34}$ The chromatograms of the extracts from the water fortified with anilazine, linuron, prothiofos, and tebuconazole showed peaks at retention times of 5.3, 4.9, 5.6, and $6.35 \mathrm{~min}$, respectively. The absence of any signal at the retention time of the analytes for the pesticide-free matrix indicated that there were no matrix compounds that could give a false positive signal (Annex 1).
Thus, the optimized method is selective when used in the study of anilazine, linuron, prothiofos, and tebuconazole in water.

Linearity corresponds to the ability of the method to provide results directly proportional to the concentration of the analyte under analysis within a given application range. ${ }^{33,35}$ The main parameter used to estimate the linearity of the method is the correlation coefficient (r) of the calibration curve. ${ }^{33}$ The adjusted equations of anilazine $(y=9000000 x-54700 ; r=0.9950)$, linuron $(y=2000000 x-23192$; 
$\mathrm{r}=0.9980)$, prothiofos $(\mathrm{y}=9000000 \mathrm{x}-20084 ; \mathrm{r}=0.9971)$, and tebuconazole $(\mathrm{y}=8000000 \mathrm{x}-38121 ; \mathrm{r}=0.9943)$ showed the good linearity of the method and a strong correlation between the concentration of the analyte and the chromatographic area at the concentration range studied.

The values of LOD and LOQ were 0.005 and $0.016 \mathrm{mg} \mathrm{L}^{-1}$ for anilazine, 0.007 and $0.022 \mathrm{mg} \mathrm{L}^{-1}$ for linuron, 0.005 and $0.016 \mathrm{mg} \mathrm{L}^{-1}$ for prothiofos, and 0.007 and $0.020 \mathrm{mg} \mathrm{L}^{-1}$ for tebuconazole, respectively. These values were obtained using the method based on the calibration curve parameters with a working range of $0.05-0.15 \mathrm{mg} \mathrm{L}^{-1}$ for each of the pesticides considering the enrichment factor of the technique as 142.4 times $(45000 \mu \mathrm{L} / 316 \mu \mathrm{L})$.

The accuracy and precision values obtained by the VALLME method in the analysis of the samples of deionized water fortified with pesticides in different concentrations are available in Table 3.

The accuracy of an analytical method is the proximity of the results obtained by the test method to the true value using an experimental procedure for the same sample several times. ${ }^{36}$ For the analysis of the residues, the analytical procedure must be capable of recovering an average residue of 80 to $110 \%{ }^{37}$ at each level of fortification. Therefore, the presented values of accuracy (Table 3) are in accordance with the standard. Thus, the developed method is reliable for the extraction and analysis of anilazine, linuron, prothiofos, and tebuconazole in water.

The precision was calculated by evaluating the values of the coefficient of variation $(\mathrm{CV})$ of the obtained results. ${ }^{21,38}$ According to Ribani et al. ${ }^{33} \mathrm{CV}$ values up to $20 \%$ are acceptable, depending on the complexity of the sample to be analysed. The results obtained demonstrate the good performance of the method.

There is a considerable difference between the limits established by the environmental agencies of each country in relation to the acceptable limits of residues in water and food. In Brazil, there is no specific legislation for the limits of pesticides present in wastewater. In the European Union, the maximum acceptable concentration of pesticides in industrial wastewater before discharge into sewers or aquatic environments is $0.05 \mathrm{mg} \mathrm{L}^{-1} \cdot 39,40$

Portaria de Consolidação $\mathrm{n}^{\mathrm{o}} 5$ of 28 September $2017,{ }^{41}$ which establishes procedures for the control and monitoring of the quality of water for human consumption and its standard of potability throughout the national territory, establishes standards of potability for chemical substances that represent a health risk. Among the analysed analytes, only tebuconazole was cited, with an acceptable maximum limit of $180 \mu \mathrm{g} \mathrm{L} \mathrm{L}^{-1}$. In the European Union, the limit is only $0.1 \mu \mathrm{g} \mathrm{L}{ }^{-1} .^{42}$

Compared with conventional methods, the viability of the proposed method (VALLME) for the analysis of the pesticides anilazine, linuron, prothiofos, and tebuconazole in water samples demonstrated that VALLME was easy and fast to execute without the necessity of the centrifugation step and/or an additional solvent. The limits of quantification presented were acceptable since they were below both the limit required by Brazilian Portaria de Consolidação $\mathrm{n}^{\mathrm{o}} 5$ for drinking water and the European Union limit for wastewater.

\section{Matrix effect}

In the chromatographic analysis of complex samples, the responses attributed to pesticides may undergo changes due to matrix interference. These changes are called the array effect. This phenomenon is used to explain rates of pesticide recovery that exceed $100 \%$ and the low accuracy of the results. ${ }^{43}$ Generally, a matrix effect is observed when a considerable difference in the chromatographic response is obtained between the standards prepared in the solvent and those prepared in the matrix extract. ${ }^{44}$ This effect may be positive (signal increase) or negative (signal decrease) on the result of the analysis. These changes are a consequence of the adsorption of the analytes and the matrix components in the injector, the detector and/ or in the chromatographic column. ${ }^{45}$

For example, Annex 1 shows the chromatograms of the extract obtained from samples of pure water fortified with linuron, anilazine, prothiofos, and tebuconazole at a concentration of $0.1 \mathrm{mg} \mathrm{L}^{-1}$ (A) and wastewater from the washing process and peeling of potatoes fortified at a concentration of $1 \mathrm{mg} \mathrm{L}^{-1}$ with the same pesticides (B).

The regression equations adjusted for the standards of the pesticides anilazine, linuron, prothiofos, and tebuconazole prepared in pure water and wastewater from the potato washing and peeling process and extracted according to the optimized VALLME method are presented in Figure 5 as a function of the response $\left(\mathrm{mg} \mathrm{L}^{-1}\right)$ with their determination coefficients $\left(\mathrm{R}^{2}\right)$ and the equations that describe the slope of the analytical curve and their respective matrix effect in Table 4.

In the study of the matrix effect of the extraction method for pure water and wastewater samples (Table 4), it was observed that for linuron and prothiofos, the co-extractives of the wastewater samples caused suppression in the chromatographic response of 7.82 and $27.63 \%$, respectively.

Table 3. Recoveries and coefficients of variation $(\mathrm{CV})$ of the VALLME method obtained by analysing samples of pure water fortified with pesticides ( $\mathrm{n}=6$ points)

\begin{tabular}{|c|c|c|c|c|}
\hline \multirow{3}{*}{ Analytes } & \multirow{3}{*}{$\begin{array}{l}\text { Nominal concentration } \\
\qquad\left(\mathrm{mg} \mathrm{L}^{-1}\right)\end{array}$} & \multirow{3}{*}{$\begin{array}{c}\text { Accuracy } \\
\text { Recovery (\%) }\end{array}$} & \multicolumn{2}{|c|}{ Precision } \\
\hline & & & Repeatability & Intermediate precision \\
\hline & & & \multicolumn{2}{|c|}{ Coefficient of variation (\%) } \\
\hline \multirow{3}{*}{ Anilazine } & 0.100 & 89.85 & 4.57 & 10.45 \\
\hline & 0.125 & 90.16 & 3.45 & 8.98 \\
\hline & 0.150 & 95.43 & 4.41 & 8.14 \\
\hline \multirow{3}{*}{ Linuron } & 0.100 & 91.27 & 9.04 & 15.08 \\
\hline & 0.125 & 89.01 & 1.30 & 10.99 \\
\hline & 0.150 & 89.06 & 5.99 & 14.13 \\
\hline \multirow{3}{*}{ Prothiofos } & 0.100 & 89.23 & 1.26 & 10.70 \\
\hline & 0.125 & 89.93 & 2.48 & 8.11 \\
\hline & 0.150 & 92.02 & 1.35 & 9.21 \\
\hline \multirow{3}{*}{ Tebuconazole } & 0.100 & 91.32 & 1.91 & 10.87 \\
\hline & 0.125 & 89.84 & 1.47 & 8.67 \\
\hline & 0.150 & 94.82 & 4.28 & 10.37 \\
\hline
\end{tabular}




\section{Pure water}
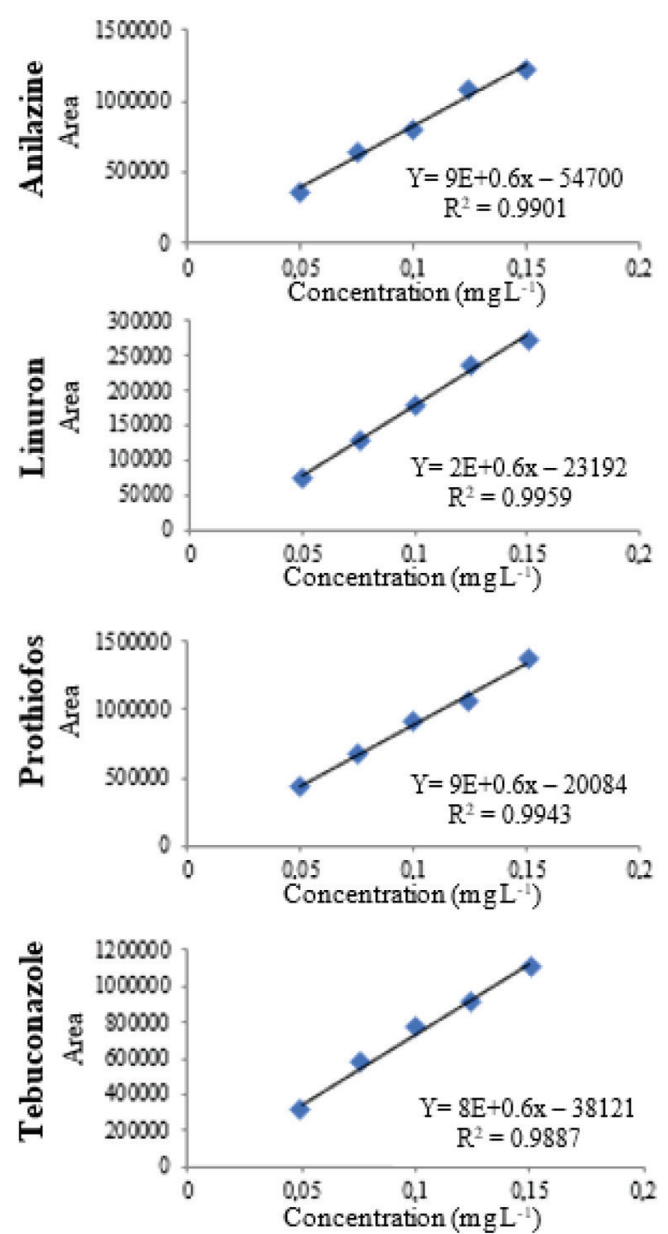

wastewater
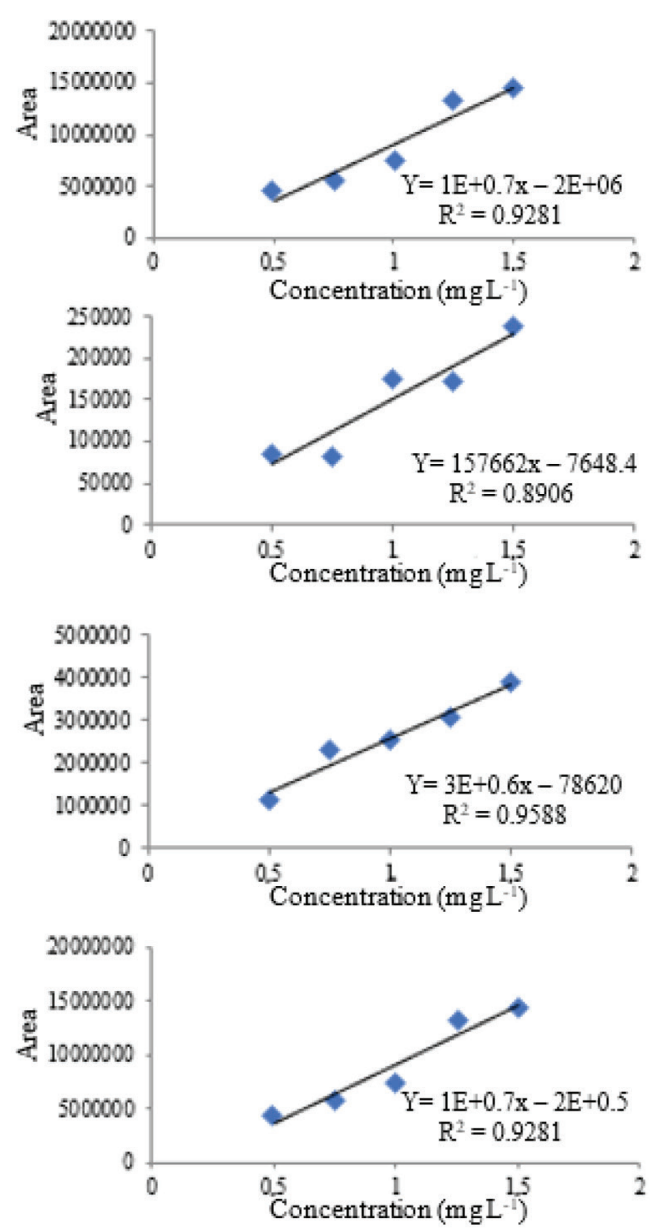

Figure 5. Calibration curves obtained by the VALLME extraction method of the standards of the pesticides anilazine, linuron, prothiofos, and tebuconazole prepared in pure water (left) and wastewater from the washing and peeling process of potatoes (right)

Table 4. Slope of the calibration curves obtained by the VALLME extraction method of the standards of the pesticides anilazine, linuron, prothiofos, and tebuconazole prepared in pure water and wastewater from the washing and peeling process of potatoes and their respective matrix effect $(\mathrm{n}=3$ points)

\begin{tabular}{lcccc}
\hline Pesticide & $\begin{array}{c}\text { Slope of the calibration curve for } \\
\text { pure water } \pm \mathrm{SD}\end{array}$ & $\begin{array}{c}\text { Slope of the calibration curve for the } \\
\text { wastewater of potatoes }\end{array}$ & $\mathrm{T}_{\text {calc }}$ & Matrix effect $(\%)$ \\
\hline Anilazine & $8775470.45 \pm 505438.16$ & $10997516.62 \pm 1766779.57$ & 1.21 & - \\
Linuron & $2017061.28 \pm 74761.33$ & $157661.99 \pm 31902.64$ & $58.28 *$ & $13.18^{*}$ \\
Prothiofos & $9100915.33 \pm 398971.57$ & $2514902.29 \pm 300900.08$ & 1.77 & 27.63 \\
Tebuconazole & $7755278.48 \pm 479048.04$ & $10997516.62 \pm 1766779.57$ & - \\
\hline
\end{tabular}

$\mathrm{SD}=$ standard deviation. *Significant at $5 \%$ by Student's t-test.

\section{Application in wastewater samples}

The identification of the pesticides anilazine, linuron, prothiofos, and tebuconazole was carried out by comparing the retention times of the analytes in a standard solution (pure water fortified with each of the pesticides) and in the samples of wastewater from the washing and peeling process of potatoes collected in a straw factory, wastewater from the manual washing process of dirty potatoes purchased in a local market and water used for irrigation collected from a dam located in an area with potato planting. The results showed that the concentrations of the target analytes found in the analysed water samples were lower than the LOD of the proposed method. In these samples, none of the analytes studied were detected. Despite this, it is important to note that these results do not attest to the absence of pesticide contamination risk of the water resources in the sample collection region. To do so, a more detailed evaluation involving other active principles used in the potato planting region and the periodic collection of samples would be required.

\section{CONCLUSIONS}

The developed VALLME method was selective for the pesticides under study and presented good linearity and precision, with low limits of detection (LOD) and quantification (LOQ) of 0.005 and $0.016 \mathrm{mg} \mathrm{L}^{-1}$ for anilazine, 0.007 and $0.022 \mathrm{mg} \mathrm{L}^{-1}$ for linuron, 0.005 and $0.016 \mathrm{mg} \mathrm{L}^{-1}$ for prothiofos, and 0.007 and $0.020 \mathrm{mg} \mathrm{L}^{-1}$ for tebuconazole, respectively.

In the study of the matrix effect of the extraction method for pure 
water and wastewater of potato processing, for linuron and prothiofos, the co-extractives of the potato wastewater caused suppression in the chromatographic response of 7.82 and $27.63 \%$, respectively.

The concentrations of the target analytes found in the waste samples (wastewater from the industrial potato washing process, wastewater from the manual washing of potatoes and dam water) were lower than the LDs of the proposed method. In these samples, none of the analytes studied were detected.

\section{SUPPLEMENTARY MATERIAL}

Chromatograms of the studied pure, wastewater and residual water samples are freely available at http://quimicanova.sbq.org.br, in pdf format.

\section{ACKNOWLEDGMENTS}

The authors are grateful for the financial support of Fundação de Amparo à Pesquisa do Estado de Minas Gerais (FAPEMIG) and Conselho Nacional de Desenvolvimento Científico e Tecnológico $(\mathrm{CNPq})$. This study was financed in part by the Coordenação de Aperfeiçoamento de Pessoal de Nível Superior - Brasil (CAPES) Finance Code 001.

\section{REFERENCES}

1. Pinto, M. I.; Sontag, G.; Bernardino, R. J.; Noronha, J. P.; Microchem. J. 2010, 96, 225.

2. Rizzetti, T. M.; Kemmerich, M.; Martins, M. L.; Prestes, O. D.; Adaime, M. B.; Zanella, R.; Food Chem. 2016, 196, 25.

3. Tadeo, J. L.; Albero, B.; Pérez, R. A. In Analysis of Pesticides in Food and Environmental Samples; Tadeo, J. L., ed.; CRC Press: Boca Raton, 2009.

4. ATLAS; Geografia do Uso de Pesticidas no Brasil e Conexões com a União Europeia, Bombardini, L. M., ed.; Laboratório de Geografia Agrária, FFLCH - USP: São Paulo, 2017.

5. Larramendi, C. H.; Alergol. Inmunol. Clin. 2003, 18, 129.

6. Prestes, O. D.; Friggi, C. A.; Adaime, M. B.; Zanella, R.; Quim. Nova 2009, 32, 1620.

7. AGRIANUAL; Anuário da Agricultura Brasileira, FNP - Consultoria \& Agroinformativos: São Paulo, 2017, pp. 161-162.

8. França, F. C. F.; Moreira, D. R.; Almeida, R. R.; Rodrigues, F. H. A.; Ribeiro, M. E. N. P.; Ricardo, N. M. P. S.; Quim. Nova 2017, 40, 247.

9. Zárate, N. A. H.; Vieira, M. C.; Araújo, C.; Ciênc. Agrotec. 2001, 25, 1337.

10. Handford, C. E.; Elliott, C. T.; Campbell, K.; Integr. Environ. Assess. Manage. 2015, 11, 525 .

11. Farajzadeh, M. A.; Djozan, D.; Mogaddam, M. R. A.; Bamorowat, M.; J. Sep. Sci. 2011, 34, 1309.

12. Chen, H.; Chen, R.; Li, S.; J. Chromatogr. A 2010, 1217, 1244.

13. APHA; Standard Methods for the Examination of Water and Wastewater Procedures, American Public Health Association, Part 6000 Individual organic compounds, 2012.

14. Pebdani, A. A.; Shabani, A. M. H.; Dadfarnia, S.; Talebianpoor, M. S.; Khodadoust, S.; J. Sep. Sci. 2016, 39, 1935.

15. Ahmadi, F.; Assadi, Y.; Hosseini, S. M. R. M.; Rezaee, M.; J. Chromatogr. A 2006, 1101, 307.

16. Bosch Ojeda, C.; Sánchez Rojas, F.; Chromatographia 2014, 77, 745.

17. Yiantzi, E.; Psillakis, E.; Tyrovola, K.; Kalogerakis, N.; Talanta 2010, 80, 2057.

18. Saleh, A.; Yamini, Y.; Faraji, M.; Rezaee, M.; Ghambarian, M.; $J$. Chromatogr. A 2009, 1216, 6673.
19. Su, Y.-S.; Jen, J.-F.; J. Chromatogr. A 2010, 1217, 5043.

20. Duarte, J. da S.; Dores, E. F. G. de C.; Villa, R. D.; Quim. Nova 2016, $39,925$.

21. INMETRO; DOQ-CGCRE-008 - Revisão 05: Orientação sobre validação de métodos analíticos, Rio de Janeiro, 2016, 31p.

22. Meier, P. C.; Zünd, R. E.; Statistical Methods in Analytical Chemistry, John Wiley \& Sons, Inc.: Hoboken, 2000.

23. Jia, C.; Zhu, X.; Wang, J.; Zhao, E.; He, M.; Chen, L.; Yu, P.; J. Chromatogr. A 2010, 1217, 5868.

24. Nojavan, S.; Gorji, T.; Davarani, S. S. H.; Morteza-Najarian, A.; Anal. Chim. Acta 2014, 838, 51.

25. Tolcha, T.; Merdassa, Y.; Megersa, N.; J. Sep. Sci. 2013, 36, 1119.

26. Fontana, A. R.; Wuilloud, R. G.; Martínez, L. D.; Altamirano, J. C.; J. Chromatogr. A 2009, 1216, 147.

27. Ozcan, S.; Tor, A.; Aydin, M. E.; Anal. Chim. Acta 2010, 665, 193.

28. Wu, Q.; Li, Z.; Wu, C.; Wang, C.; Wang, Z.; Microchim. Acta 2010, 170, 59.

29. Trtić-Petrović, T.; Dimitrijević, A.; Open Chem. 2014, 12, 98.

30. Maddah, B.; Javadi, S. S.; Mirzaei, A.; Rahimi-Nasrabadi, M.; J. Liq. Chromatogr. Relat. Technol. 2015, 38, 208.

31. Nunes, C. A.; Freitas, M. P.; Pinheiro, A. C. M.; Bastos, S. C.; J. Braz. Chem. Soc. 2012, 23, 2003.

32. Li, M.; Dai, C.; Wang, F.; Kong, Z.; He, Y.; Huang, Y. T.; Fan, B.; Sci. Rep. 2017, 7, 42489

33. Ribani, M.; Bottoli, C. B. G.; Collins, C. H.; Jardim, I. C. S. F.; Melo, L. F. C.; Quim. Nova 2004, 27, 771.

34. Paschoal, J. A. R.; Rath, S.; Airoldi, F. P. da S.; Reyes, F. G. R.; Quim. Nova 2008, 31, 1190 .

35. Swartz, M. E.; Krull, I. S.; Pharm. Technol. 1998, 2, 12.

36. Thompson, M.; Ellison, S. L. R.; Wood, R.; Pure Appl. Chem. 2002, 74, 835.

37. MAPA; Manual de garantia da qualidade analítica; Brasília, 2011, 227 p., available at https://bibliotecaquimicaufmg2010.files.wordpress. com/2012/02/mapa-2011-manual-de-garantia-da-qualidade-analitica. pdf, accessed at June 2020

38. European Comission; Analytical Quality Control and Method Validation Procedures for Pesticide Residues Analysis in Food and Feed, Document N SANTE/2015/11945, 2015, available at https://www.eurol-pesticides. eu/library/docs/allcrl/AqcGuidance_SANTE_2015_11945.pdf, accessed at June 2020.

39. Diputación Barcelona; Mancomunitat Intermunicipal del Penedès i Garraf, Reglament d'abocaments d'aigües residuals, 2001, available at https://www.cido.diba.cat/normativa_local/29547/reglamentdabocaments-daigues-residuals-mancomunitat-intermunicipal-delpenedes-i-garraf, accessed at June 2020.

40. European Union; Directive 76/464/EEC of May 1976 on pollution caused by certain dangerous substances discharged into the aquatic environment of the Community, 1976, available at https://eur-lex.europa. eu/legal-content/EN/TXT/?uri=CELEX\%3A31976L0464, accessed at June 2020.

41. Ministério da Saúde; Portaria De Consolidação No 5 , de 28 de Setembro de 2017, 2017, available at https://portalaquivos2.saude.gov.br/images/ pdf/2018/marco/29/PRC-5-Portaria-de-Consolida---o-n---5--de-28-desetembro-de-2017.pdf, accessed at June 2020.

42. European Union; Council Directive 98/83/EC of 3 November of 1998 on the quality of water intended for human consumption, 1998, available at https://eur-lex.europa.eu/legal-content/EN/ TXT/?uri=CELEX\%3A31998L0083, accessed at June 2020.

43. Hajšlová, J.; Holadová, K.; Kocourek, V.; Poustka, J.; Godula, M.; Cuhra, P.; Kempný, M.; J. Chromatogr. A 1998, 800, 283.

44. Picó, Y.; Blasco, C.; Font, G.; Mass Spectrom. Rev. 2004, 23, 45.

45. Hajšlová, J.; Zrostlíková, J.; J. Chromatogr. A 2003, 1000, 181. 